\title{
Artificial nutrition and hydration: science, ethics and law
}

\author{
J Mcllmoyle and MJ Vernon
}

J Mcllmoyle MRCP, Specialist Registrar,

Department of Elderly Medicine, Manchester Royal Infirmary

MJ Vernon

MRCP, Consultant

Geriatrician,

Department of

Elderly Medicine,

Wythenshawe

Hospital,

Manchester

Clin Med

2003;3:176-8

This conference was held at the

Royal College of

Physicians on

11 December 2002
The technology exists whereby patients can be provided with nutrition and hydration artificially, but is it always ethical to do so? Clinicians often feel ill equipped when faced with decisions regarding the withholding or withdrawal of food and fluids. This conference explored the scientific, ethical and legal boundaries of current practice.

\section{Feeding following stroke}

The scientific knowledge base for feeding following stroke is poor. It is unknown whether early nutritional support improves mortality and dependency. Optimal technique for feeding is also unclear, ie nasogastric (NG) tube or percutaneous endoscopic gastrostomy (PEG). These questions are being addressed by the Feed Or Ordinary Diet (FOOD) trial for which recruitment is ongoing. Complications of PEG insertion should be addressed when counselling patients and their relatives about this procedure. Many patients with dysphagia have communication problems and this raises issues of obtaining consent. Sometimes this can be overcome by the use of pictures explaining the procedure. However, in many cases medical professionals must proceed in the best interests of the patient.

\section{Conference programme}

I Feeding following stroke

Professor Martin Dennis, University of Edinburgh

I Feeding the peri-operative patient

Mr John MacFie, Scarborough Hospital

- Clinical approach to the withdrawal of nutrition and hydration

Dr Keith Andrews, Institute of Complex Neuro-Disabilities, London

I Fluid, electrolytes and nutrition

Professor Simon Allison, Queen's Medical Centre Nottingham

I Withholding food and water: some moral problems

Dr Helen Watt, The Linacre Centre for Healthcare Ethics, London

- There is no absolute right to food and water

Professor Søren Holm, University of Manchester

I Dispute about life-sustaining treatment and public policy Ms Hilary Scott, Office of the Health Service Commissioner for England

- Withdrawing food and water: the legal constraints

Dr John Keown, University of Cambridge

\section{Feeding the peri-operative patient}

Lack of nutrition for seven or more days amounts to starvation and needs to be remedied by the supply of nutrients. A malnourished patient awaiting surgery raises difficult clinical and ethical questions. Should the patient be fed? If so, when and how? In a competent patient, consent is required before artificial feeding can commence. Competence requires that the patient understand, retain and be able to weigh and express their choice. Adults are assumed to be competent until assessed as incompetent. However, even a competent patient cannot demand artificial feeding where it is deemed to be futile, for example in the end stage of terminal illness. To avoid negligence, a doctor is required to act in accordance with a responsible body of medical opinion and in the patient's best interests. Where the value of intervention is not clear, a time-limited trial of feeding with specified outcomes may determine efficacy.

Over the last few decades, ethicists have had to respond to advances in medical technology; in particular, about when to withhold or withdraw nutrition since technically all patients can be fed. However, there has also been a change in the doctor-patient relationship. Increasing respect for patient autonomy necessitates giving correct and appropriate information to facilitate freedom of choice. Advance directives may become more prevalent as more individuals make proviso for a degree of autonomy even after the onset of incompetence. An additional pressure on patient care is the responsible use of scarce resources, and the utilitarian perspective can influence individual patient management. Responding to these pressures on twentieth century ethics, the Tavistock principles ${ }^{1}$ aim to provide a workable framework for medical practitioners.

\section{Clinical approach to the withdrawal of nutrition and hydration}

The question of withdrawal of artificial nutrition and hydration in medically stable patients most commonly arises in cases of persistent vegetative state. Requests mostly come from the patient's family but could come from another interested person, the clinician looking after the patient or potentially (but so far not actualised) a lawyer. The necessary steps of whole family discussion, accurate diagnosis and 
application to the High Court have to be completed. The questions that need to be addressed in the Court application are shown in Box 1. It is important that the clinical team agrees on management and that both they and the family are supported by counsellors throughout. In withdrawing nutrition, the feeding tube must be removed since it is the tube that is the medical intervention. Not to feed a patient with a feeding tube in situ could leave the nursing staff open to charges of neglect. After the tube is removed, peaceful death usually ensues within seven to ten days due to dehydration.

The same questions regarding patients with a minimal level of consciousness, termed glimmering awareness, could create greater legal and ethical difficulty. This condition has recently been defined as 'severely altered consciousness in which the patient does not meet the criteria for coma or the vegetative state because there is inconsistent but reproducible or sustained behavioural evidence of self or environmental awareness'. It will be only a matter of time before such a case is brought before the Court. However, it remains to be seen if the principles developed for the Bland case ${ }^{2}$ will be extended to such situations.

\section{Withholding food and water: some moral problems}

Dr Helen Watt spoke about the importance of intent when deciding the morality of an action. Removing a feeding tube is acceptable if the intent is to relieve suffering, ie the disadvantages of feeding outweigh the benefit to the patient. However, to stop feeding with the intent of ending life is morally unacceptable. It is recognised that feeding a terminally ill patient can increase suffering since often in this situation the gastrointestinal tract can no longer efficiently process food. Rejecting the dualism of mind and body, she insists that the body, as part of the 'human animal', has absolute worth and therefore should not be starved with the intent of causing death. Can a life ever be deemed worthless? Even in a persistent vegetative state (PVS) the person has lost a great deal but they are nevertheless of value to their family and carers. This position is supported by the fact that we do not perform inhumane experiments on PVS patients. Notwithstanding, this position could also be explained in terms of the memory of previous personhood, which we also apply to dead people.

A patient wanting to die (regardless of cause) should be prevented from 'committing suicide' in the same way as a person taking an overdose. A distinction was made, however, between a

\section{Box 1. Questions to be addressed in Court applications to stop artificial nutrition and hydration.}

- What is the diagnosis?

- Is there anything hiding the diagnosis?

- What is the prognosis for recovery?

- What is the life expectancy?

- Has everything been done?

- What are the options if the tube is not withdrawn?

- What will happen if the tube is withdrawn?

- What are the views of the family? patient refusing life-prolonging treatment because of unpleasant side effects, for example chemotherapy, and refusing the same treatment simply on the grounds that they wanted to die.

\section{There is no absolute right to food and water}

A competent person can waive his right to food and water and be considered a hero if he does so for some higher cause, as in the case of hunger strikers. Taking issue with the idea that withholding food was an act of abandonment, Professor Holm noted that we do not always think similarly when considering the starving of other countries. When faced with inevitable circumstances (eg famine from natural disaster, futility of medical treatment), it is not our actions but our omissions to act which require moral evaluation. Anticipated poor outcome does not, of itself, create obligation to act. Countering Dr Watt's argument that refusal of food and fluid is equivalent to an act of suicide, he noted that the term was only useful if used in the context of a depressed person taking their own life. There are no moral objections to a rational person taking their own life and no ethical reasons for others to intervene. If it was acceptable to withhold other treatments, it was acceptable to withhold artificial hydration and nutrition.

After a lively exchange of views, the audience was asked for a show of hands if they would want artificial feeding in the event of being rendered minimally conscious. An overwhelming majority did not want intervention.

\section{Withdrawing food and water: the legal constraints}

Discussing Bland, ${ }^{2}$ three out of the five Law Lords had agreed to stopping feeding with the specified 'intent' to end the life of Tony Bland. Competent adults have the right to refuse any treatment including food and fluids. Valid advance refusals (made voluntarily by informed and competent individuals) applying to the patient's current situation are legally binding. The British Medical Association and the General Medical Council guidelines $^{4}$ on withdrawal of artificial nutrition and hydration represents the body of responsible peers required by Bolam ${ }^{5}$ to establish acceptable practice. The guidelines go beyond the case of PVS and could apply to minimally conscious patients or those with severe stroke or dementia. In Professor Keown's view, it is unlikely that a court of law would prosecute a doctor for acting in accordance with professional guidelines despite the absence of case law in these circumstances. This surprising conclusion raised concern among professionals that any attempts to extend the Bland principle beyond cases of PVS could nevertheless be challenged in the civil courts. Professor Keown observed that since the Bland ruling, consent case law is 'morally and intellectually misshapen' but this precedent is unlikely to be overruled.

\section{Conclusion}

This conference succeeded in exploring the scientific, legal and ethical issues which surround withholding or withdrawing artificial nutrition and hydration. The competent patient has the 
right to refuse any treatment including food and water. Valid advance directives, whether written or verbal, which refuse treatment pertaining to a patient's current situation are legally binding. Incompetent patients must be treated in their best interests. Where there is clinical uncertainty, a time-limited trial of food and fluid is justifiable. The emotive issues which surround withdrawing artificial nutrition and hydration often impede rational debate. One approach is to consider the balance of rights of the individual - is a patient's right to life inalienable, or should greater respect be afforded to the patient's right to choose? This conference, attended by a wide range of professional groups, delivered consensus in favour of personal choice which may override an absolute right to life. It remains to be seen whether the public will utilise advance directives to articulate a similar view.

\section{References and cases}

1 Berwick D, Davidoff F, Hiatt H, Smith R. Refining and implementing the Tavistock principles for everybody in health care. BMJ 2001;323: 616-20.

2 Airdale NHS Trust v Bland [1993] 1 All ER 821.

3 Lobo DN, Neal KR, Perkins AC, Rowlands BJ, Allison SP. Effect of salt and water balance on recovery of gastrointestinal function after elective colonic resection: a randomised controlled trial. Lancet 2002;359: 1812-18.

4 General Medical Council and British Medical Association. Withholding and withdrawing life prolonging treatments: good practice in decision making. London: GMC, 2002.

5 Bolam v Friern Hospital Management Committee [1957] 1 BMLR 1. 